\title{
Survival disparities in Australia: an analysis of patterns of care and comorbidities among indigenous and non-indigenous cancer patients
}

\author{
Suzanne P Moore ${ }^{1,4^{*}}$, Adèle C Green ${ }^{2,3}$, Freddie Bray ${ }^{4}$, Gail Garvey ${ }^{1}$, Michael Coory ${ }^{5}$, Jennifer Martin ${ }^{6,7}$
} and Patricia C Valery ${ }^{1}$

\begin{abstract}
Background: Indigenous Australians have lower overall cancer survival which has not yet been fully explained. To address this knowledge deficit, we investigated the associations between comorbidities, cancer treatment and survival in Indigenous and non-Indigenous people in Queensland, Australia.

Methods: A cohort study of 956 Indigenous and 869 non-Indigenous patients diagnosed with cancer during 1998-2004, frequency-matched on age, sex, remoteness of residence and cancer type, and treated in Queensland public hospitals. Survival after cancer diagnosis, and effect of stage, treatment, and comorbidities on survival were examined using Cox proportional hazard models.

Results: Overall Indigenous people had more advanced cancer stage $(p=0.03)$, more comorbidities $(p<0.001)$, and received less cancer treatment ( $77 \%$ vs. $86 \%, p=0.001)$. Among patients without comorbidities and social disadvantage, there was a lower uptake of treatment among Indigenous patients compared to non-Indigenous patients. For those who received treatment, time to commencement, duration and dose of treatment were comparable. Unadjusted cancer survival $(\mathrm{HR}=1.30,95 \% \mathrm{Cl} 1.15-1.48)$ and non-cancer survival $(\mathrm{HR}=2.39,95 \% \mathrm{Cl}$ 1.57-3.63) were lower in the Indigenous relative to non-Indigenous patients over the follow-up period. When adjusted for clinical factors, there was no difference in cancer-specific survival between the groups $(H R=1.10$, $95 \% \mathrm{Cl}$ 0.96-1.27). One-year survival was lower for Indigenous people for all-causes of death (adjusted HR=1.33, $95 \%$ Cl 1.12-1.83).

Conclusion: In this study, Indigenous Australians received less cancer treatment, had more comorbidities and had more advanced cancer stage at diagnosis, factors which contribute to poorer cancer survival. Moreover, for patients with a more favourable distribution of such prognostic factors, Indigenous patients received less treatment overall relative to non-Indigenous patients. Personalised cancer care, which addresses the clinical, social and overall health requirements of Indigenous patients, may improve their cancer outcomes.
\end{abstract}

Keywords: Indigenous, Cancer, Diabetes, Comorbidity, Disparity, Cancer stage, Survival, Queensland

\footnotetext{
* Correspondence: Suzanne.Moore@menzies.edu.au

'Menzies School of Health Research, 147 Wharf St, Spring Hill, Brisbane 4000,

Australia

${ }^{4}$ International Agency for Research on Cancer, 150 Cours Albert Thomas,

69372 Lyon, France

Full list of author information is available at the end of the article
}

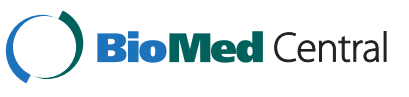

(c) 2014 Moore et al.; licensee BioMed Central Ltd. This is an Open Access article distributed under the terms of the Creative Commons Attribution License (http://creativecommons.org/licenses/by/4.0), which permits unrestricted use, distribution, and reproduction in any medium, provided the original work is properly credited. The Creative Commons Public Domain Dedication waiver (http://creativecommons.org/publicdomain/zero/1.0/) applies to the data made available in this article, unless otherwise stated. 


\section{Background}

In Australia, cancer is the second leading cause of death among Indigenous people, who continue to experience a significantly lower life-expectancy than the population as a whole. The observation of lower cancer survival among Indigenous compared to non-Indigenous Australians is well established [1-3] but not as yet fully explained. Factors contributing to this survival disparity include later stage of cancer at diagnosis, reduced uptake of or access to treatment, high rates of case-fatal cancers and comorbidities, and language barriers [1,4,5]. A previous study in the state of Queensland found that Indigenous people with cancer were more likely to have comorbidities, to receive less treatment, and to experience worse survival than non-Indigenous counterparts [6].

We replicated this earlier matched-cohort study design where we compared Indigenous and non-Indigenous people with cancer, this time including a larger cohort, collecting more comprehensive and detailed information on cancer treatment (e.g. timing to, type and amount of treatment) and comorbidities. Here we examine the associations between comorbidities, cancer treatment and survival among Indigenous and non-Indigenous cancer patients in Queensland, the state with the second-largest Indigenous population in Australia.

\section{Methods}

Methods for this comparative study of Indigenous and non-Indigenous cancer patients are similar to those described previously [6,7]. Briefly, all Indigenous adults residing in the state of Queensland and diagnosed with cancer during 1998-2004, identified through the population-based Queensland Cancer Registry (QCR), were eligible for inclusion. An equal number of non-Indigenous cases were randomly identified from the Registry (frequency-matched for age, sex, remoteness and cancer type). All Australian residents have access to free publichealth care, including cancer treatment, and those with private insurance, or the means to pay, can also access treatment in the private sector [6]. We restricted our cohort to those who received the majority of treatment in a Queensland public hospital, as about 98\% of Indigenous patients receive care in the public sector [8]. Patients primarily treated elsewhere, those with missing health records, or those treated in a hospital where regulatory approval was not forthcoming, were excluded.

Clinical data (diagnostic details, cancer treatment, cancer stage, and presence of comorbidities), were abstracted from medical records, as this information was not available from the QCR. Where records were insufficiently detailed, further data were extracted from secondary public hospitals' records, to ensure that cancer treatment and other clinical data were as complete as possible. In general, details of surgery, chemotherapy or radiotherapy treatment that occurred outside the public hospital system were documented in the public health records, through treating clinician's letters. Details on all comorbidities recorded in the patients' medical records were extracted; comorbidities that fitted with the Charlson Comorbidity Index Score (CCI) were included in the analysis. A modified CCI score (referred to here as 'comorbidity score') was assigned based on severity and number of comorbid conditions [9] and were grouped as: 0 (No known comorbidity), 1, 2+. Modification of the original CCI was necessary where data on the severity of renal or liver disease were not collected; these were classified as 2 . Remoteness (rurality of residence) was determined using the Accessibility/Remoteness Index of Australia [10] with groups ranging from 1 'highly accessible' and 5 'very remote'. For multivariate analysis, the categories were aggregated to three groups; 1 (highly accessible and accessible), 2 (moderately accessible) and 3 (remote and very remote). The Socio-Economic Index For Areas (SEIFA) was used to classify place of residence into quintiles ranging from 1 'most disadvantaged' to 5 'most advantaged' [11].

Cancer stage scores such as Tumour Nodes Metastasis (TNM), Dukes and American Joint Committee on Cancer (AJCC) [12] staging were converted to localised/regional/ distant spread. Treatment type (surgery, radiotherapy and chemotherapy), intention (any intent, curative intent or intention unknown), start date, duration, and quantity (e.g. number of Gray (Gy), number of chemotherapy cycles) were recorded. Date and cause of death were obtained from the Australian National Death Index. All cases were followed-up with respect to their vital status until Dec 31, 2006.

Ethical approval was obtained from the Queensland Health Department, health districts where data collection took place, and the Queensland Institute of Medical Research.

\section{Statistical methods}

Pearson's Chi-squared analysis or Fisher's Exact test were used for categorical data (proportions), t-test for normally-distributed data (means), and non-parametric tests (Kruskal-Wallis Test) for non-normally-distributed data (medians). We estimated the relative risk of no treatment associated with comorbidity by calculating the odds ratios (OR) and 95\% confidence interval (CI) using multivariate logistic regression analysis. Time to death was assessed using Kaplan-Meier survival curves. The curves were compared with the log-rank test statistic. Cox proportional hazard modelling was used to calculate hazard ratios (HRs) with associated 95\% CI to assess the differences between Indigenous and non-Indigenous cases with respect to cancer survival (all-cause, cancer-specific and non-cancer), after adjustment for cancer stage, comorbidities, socioeconomic status and treatment [13]. All 
cases were followed-up from diagnosis until death or Dec 31, 2006, whichever came sooner; cases who were still alive at December 31, 2006 were censored at that date.

\section{Results}

The study included 956 Indigenous and 869 nonIndigenous patients (368 cases were excluded). Clinical data were abstracted from records at 44 hospitals. Matching resulted in similar distribution of age, sex and site of cancer diagnosis between the two groups. However, perfect matching for remoteness was not possible as fewer non-Indigenous people with cancer lived in the most remote locations at the time of diagnosis (Table 1). Indigenous people were more likely to be socially disadvantaged than their non-Indigenous counterparts $(\mathrm{p}<0.001)$ (Table 1).

Median time from presentation to diagnosis was 17 days for both groups. Cancer stage was not recorded in the clinical notes in approximately $10 \%$ of patients in both groups; a further $3 \%$ of cases in each group were diagnosed with cancers for which a stage was not routinely recorded (e.g. leukaemias, lymphomas). With these cases excluded from analysis, fewer Indigenous people were diagnosed with local disease compared to non-Indigenous people ( $38 \%$ vs. $45 \%, \mathrm{p}=0.03)$. There was no difference in cancer stage among men $(\mathrm{p}=0.65)$ but fewer Indigenous women had localised cancer ( $41 \%$ vs. $51 \%$ ), and $59 \%$ had regional spread or distant metastasis compared to $48 \%$ for non-Indigenous women $(\mathrm{p}=0.007)$. Analysis, stratified by remoteness, showed no difference in stage between Indigenous and non-Indigenous people from the same regions (data not shown).

Indigenous patients were more likely to have comorbidities than their counterparts. They were significantly less likely to have a zero comorbidity score and more likely to have a score of 2 or greater $(\mathrm{p}<0.001)$ (Table 1$)$. HbA1c, a measure of diabetes control [14], was included if tested in the year prior to diagnosis or within 3 months of diagnosis. Measurements were available for $40 \%$ of Indigenous and $21 \%$ of non-Indigenous patients with diabetes, with no difference in the proportion of cases with HbA1c over 6.5\%. Median measurements were $7.3 \%$ and $6.9 \%$ respectively, and were similar regardless of sex or remoteness.

Indigenous cancer patients received less of any treatment $(75 \%$ vs. $86 \%, \mathrm{p}<0.001)$ and for those with nonmetastatic disease, received less treatment with curative intent (Table 1). Irrespective of sex, stage, remoteness, or socioeconomic status, Indigenous people received less treatment (data not shown). Since matching was imperfect for place of residence (remoteness), in a sub-group analysis we excluded people from the most remote regions: Indigenous people from rural areas (77\% vs. $89 \%$, $\mathrm{p}<0.001)$ and those from more urban areas $(83 \%$ vs.
90\%, $\mathrm{p}=0.01$ ) received less treatment (any, surgery, chemotherapy or radiotherapy). Among patients who received treatment, modes of curative cancer treatment were similar (Figure 1). Indigenous people $(n=44)$ who concurrently lived in cities, had no known comorbidity and no metastatic cancer, and were not socially disadvantaged, took up or received less treatment than non-Indigenous counterparts $(\mathrm{n}=73)(82 \%$ vs. 95\%, $\mathrm{p}=0.05$ ) (Figure 2). Patients with diabetes and HbA1c measurements greater than $6.5 \%$ received similar rates of treatment $(\mathrm{n}=62(81 \%)$ vs. $\mathrm{n}=9(82 \%) ; \mathrm{p}=0.93)$ as those without diabetes.

Being Indigenous increased the odds of not receiving any cancer treatment and curative chemotherapy (Table 1). Stratified analyses showed that among cases who had no comorbidities recorded in the medical chart, being Indigenous increased the likelihood of not taking up or receiving any cancer treatment and curative surgery; that was also true among cases who had a comorbidity score of one.

The median time from date of diagnosis to the first cancer treatment was 14 days for Indigenous $(n=698)$ and 12 days for non-Indigenous people $(\mathrm{n}=734 ; \mathrm{p}=0.20)$. There was no significant difference in the median number of days to first surgical treatment, chemotherapy or radiotherapy between the two groups. For cases without metastatic disease, there was no difference between Indigenous and non-Indigenous people in the duration or quantity of radiotherapy (52.5 Gy respectively) or number of cycles of chemotherapy administered $(p=0.93)$. Also, there was no difference in the proportion of people with non-metastatic cancer who completed chemotherapy (76\% of Indigenous patients and $80 \%$ of non-Indigenous patients completed chemotherapy regimen; $\mathrm{p}=0.53$ ) (Table 2 ).

Compared to non-Indigenous patients, the unadjusted difference in overall survival was 37\% worse for Indigenous patients over the study period (Figure 3). Cancer-specific survival and non-cancer survival were also significantly lower (Table 3). The differential cancer-specific survival did not remain significant after adjusting for demographic and clinical factors, but persisted for non-cancer survival. Overall survival was $60 \%$ lower for Indigenous people in the first year after diagnosis, but not significantly different in subsequent years. The survival differential persisted after adjustment for demographic factors, stage, comorbidities, and treatment reduced the hazard ratio for the first year (aHR $=1.3395 \%$ CI 1.12-1.83), but not for subsequent years. Overall, survival for Indigenous people who received treatment was lower than for non-indigenous counterparts (aHR $=1.26$ 95\% CI 1.07-1.5), whereas survival was similar for those who did not receive treatment (Figure 3).

\section{Discussion}

Compared with non-Indigenous patients resident in Queensland, Australia, Indigenous people were diagnosed 
Table 1 Demographic and clinical characteristics, and patterns of care among Indigenous and non-indigenous cancer patients, Queensland, Australia 1998-2004

$\begin{array}{cc}\text { Indigenous } & \text { Non-Indigenous } \\ (\mathrm{n}=956) & (\mathrm{n}=869) \\ \mathrm{N}(\%) & \mathrm{N}(\%)\end{array}$

Age

18- 39 years

$40-59$ years

$60+$ years

Sex

male

female

Area of remoteness index

Highly accessible/Accessible

Moderately accessible

Remote/Highly remote

Socioeconomic status (SEIFA)

1 Most disadvantaged

2 Disadvantaged

3 Intermediate advantage

4 Advantaged

5 Most advantaged

Cancer stage at diagnosis*

Localised cancer

Regional Spread

Distant metastasis

Unknown or not applicable

Comorbidity score ${ }^{* *}$

0

1

$2+$

Diabetes

No

Yes

\section{HbA1C levels recorded}

Equal to or less than $6.5 \%$

Greater than 6.5\%

\section{Any cancer treatment}

Given treatment

No treatment or treatment unknown

Curative cancer treatment ${ }^{£}$

Given treatment

No treatment or treatment unknown

$\begin{array}{cc}108(11) & 91(11) \\ 421(44) & 387(45) \\ 427(45) & 391(45)\end{array}$

0.852

$436(46)$

$393(45)$

$520(54)$

$476(55)$

329 (34)

$369(43)$

370 (39)

325 (37)

257 (27)

175 (20)

$\begin{array}{cc}354(37) & 215(25) \\ 238(25) & 261(30) \\ 213(22) & 219(25) \\ 111(12) & 136(16) \\ 39(4) & 36(4)\end{array}$

316 (38)

240 (29)

336 (45)

197 (26)

275 (33)

221 (29)

$$
125
$$

$\begin{array}{ll}481(50) & 601(69) \\ 256(27) & 143(16) \\ 219(23) & 125(14)\end{array}$

$669(70)$

785 (90)

287 (30)

84 (10)

$(\mathrm{N}=113)$

$(\mathrm{N}=18)$

36 (32)

7 (39)

77 (68)

11 (61)

0.485

$716(75) \quad 745(86)$

$<0.001$

$240(25)$

$124(14)$

$\mathbf{N}=\mathbf{5 5 6}$

$\mathrm{N}=533$

400(72)

417 (78)

$153(28)$

$116(22)$

$<0.001$

$<0.001$

0.030

$<0.001$

0.030

Table 1 Demographic and clinical characteristics, and patterns of care among Indigenous and non-indigenous cancer patients, Queensland, Australia 1998-2004 (Continued)

\section{Surgery}

Surgery

No surgery or treatment unknown

$494(52)$

$462(48)$

\section{Chemotherapy}

Chemotherapy

No chemotherapy or

treatment unknown

Chemotherapy completed $\wedge$

Completed

Not completed or treatment unknown

\section{Radiotherapy}

Radiotherapy

No Radiotherapy or not sure

$325(34)$

$631(66)$

Age

18- 39 years

40 - 59 years

$60+$ years

Sex

male

female

Area of remoteness index

Highly accessible/Accessible

Moderately accessible

Remote/Highly remote

Socioeconomic status

(SEIFA)

1 Most disadvantaged

2 Disadvantaged

3 Intermediate advantage

4 Advantaged

5 Most advantaged

Cancer site and IDC code"

Bronchus and lung

(C33- C34)

Breast (C56)

Colorectal and small intestine (C17-20)

Head and neck (C00- C14)

Lymphoma and leukaemia

$83(9) \quad 84(10)$
$359(41)$

$510(59)$
$108(11) \quad 91(11)$

$421(44)$

427 (45)

$387(45)$

$391(45)$

$436(46)$

$520(54)$

$393(45)$

$476(55)$

329 (34)

$369(43)$

$325(37)$

370 (39)

257 (27)

$175(20)$

354 (37)

$215(25)$

$261(30)$

$238(25)$

$213(22)$

$219(25)$

$111(12)$

$136(16)$

$39(4)$

$36(4)$

187 (20)

$173(20)$

0.9
$<0.001$

0.530

0.001

0.852

0.870

$<0.001$

$111(12) \quad 107(12)$

$87(9) \quad 89(10)$

$61(6) \quad 55(6)$

56 (6) $\quad 49(6)$

48 (5) $\quad 30(4)$

$41(4) \quad 32(4)$

30 (4)

Cervix (C53)

Other cancers 
Table 1 Demographic and clinical characteristics, and patterns of care among Indigenous and non-indigenous cancer patients, Queensland, Australia 1998-2004 (Continued)

Renal tract (C64- C67)
Corpus uteri (C54)
Oesophagus (C15)
Other cancers
Ovary (C56)
Unknown primary (C80)
Stomach (16)
Prostate (C61)
Pancreas (C25)
Thyroid (C73)
Central Nervous System (C71)
Melanoma (C44 or M12))

Cancer stage at diagnosis*

Localised cancer
Regional Spread
Distant metastasis
Unknown or not applicable
Comorbidity score $^{* *}$
0
1
$2+$
Diabetes
No
Yes

\section{HbA1C levels recorded}

Equal to or less than $6.5 \%$

Greater than 6.5\%

Any cancer treatment

\section{Given treatment}

No treatment or treatment unknown

Curative cancer treatment ${ }^{\mathfrak{E}}$

Given treatment

No treatment or treatment unknown

\section{Surgery}

Surgery

No surgery or treatment unknown

\section{Chemotherapy}

Chemotherapy

No chemotherapy or treatment unknown

$\begin{array}{ll}40(4) & 46(5) \\ 38(4) & 36(4) \\ 31(3) & 21(2) \\ 47(5) & 35(4) \\ 29(3) & 29(3) \\ 29(3) & 17(2) \\ 27(3) & 23(3) \\ 25(3) & 17(2) \\ 22(2) & 25(3) \\ 21(2) & 14(2) \\ 13(1) & 12(1) \\ 7(1) & 10(1)\end{array}$

$\begin{array}{ccc}316(38) & 336(45) & 0.030 \\ 240(29) & 197(26) & \\ 275(33) & 221(29) & \\ 125 & 115\end{array}$

$481(50) \quad 601(69)$

$<0.001$

$256(27) \quad 143(16)$

$219(23) \quad 125(14)$

$\begin{array}{ccc}669(70) & 785(90) & <0.001 \\ 287(30) & 84(10) & \\ (\mathrm{N}=113) & (\mathrm{N}=18) & \\ 36(32) & 7(39) & 0.485 \\ 77(68) & 11(61) & \end{array}$

$716(75) \quad 745(86) \quad<0.001$

$240(25) \quad 124(14)$

$\mathrm{N}=556 \quad \mathrm{~N}=533$

$400(72) \quad 417(78)$

$153(28) \quad 116(22)$

$494(52) \quad 549(64)$

$<0.001$

$462(48) \quad 320(36)$

$269(28)$

$321(37)$

$<0.001$

$687(72) \quad 548(63)$
Table 1 Demographic and clinical characteristics, and patterns of care among Indigenous and non-indigenous cancer patients, Queensland, Australia 1998-2004 (Continued)

\begin{tabular}{|c|c|c|c|}
\hline $\begin{array}{l}\text { Chemotherapy } \\
\text { completed } \wedge\end{array}$ & $N=160$ & $N=190$ & \\
\hline Completed & $122(76)$ & $152(80)$ & 0.530 \\
\hline $\begin{array}{l}\text { Not completed or treatment } \\
\text { unknown }\end{array}$ & $38(24)$ & $38(20)$ & \\
\hline \multicolumn{4}{|l|}{ Radiotherapy } \\
\hline Radiotherapy & $325(34)$ & $359(41)$ & 0.001 \\
\hline $\begin{array}{l}\text { No Radiotherapy or } \\
\text { treatment unknown }\end{array}$ & $631(66)$ & $510(59)$ & \\
\hline \multicolumn{4}{|c|}{$\begin{array}{l}{ }^{\#} \text { International Classification of Diseases } 10 \text { th Revision (ICD-10-AM) code. } \\
{ }^{*} \text { Cases with missing data not included in analysis but numbers presented } \\
\text { for completeness. } \\
{ }^{* *} \text { Charlson Comorbidity Index: scores } 2-5 \text { and } 5+\text { were grouped. } \\
\text { Includes cases with localised and regional stage disease only. } \\
\text { NIncludes only cases with non-metastatic disease who received chemotherapy. }\end{array}$} \\
\hline
\end{tabular}

with more advanced cancer, had greater comorbidity, received less cancer treatment and were $30 \%$ more likely to die of their cancer; findings similar to those reported previously $[5,6,15]$. Concomitant disease is reported to influence cancer treatment choices (dose, duration, modality), cause complications, and impede survival [9,16-18]. Excess comorbidities have been shown to contribute to lower curative treatment rates and poorer cancer survival for New Zealand Māori [18,19], and contributed to the survival disparity among Indigenous people with lung cancer in Queensland [20]. Indigenous people with lung cancer and diabetes had reportedly $40 \%$ worse survival than Indigenous people without diabetes, whereas the presence of diabetes was unrelated to survival in nonIndigenous people [21].

In this study, stratified analysis showed that among cases without comorbidity, being Indigenous was associated with not receiving any cancer treatment, including curative surgery. This suggests that factors other than or in conjunction with comorbidity status may play a role. Of particular concern are the reasons why Indigenous people without comorbidities, who lived in an urban setting where cancer services are easily accessible, were not socially disadvantaged, and had localised cancer at diagnosis, did not have treatment. Better identification of reasons for treatment disparities in this group may enable cancer care providers to increase treatment uptake and in turn improve overall survival. Despite thorough review, we found that reasons for not receiving treatment were not routinely documented in the medical charts. We thus recommend that the views of patients and health services personnel are sought and documented to elicit and analyse barriers to treatment for Indigenous people. Our study was unable to capture sufficient information regarding comorbidities not included in the Charslon 


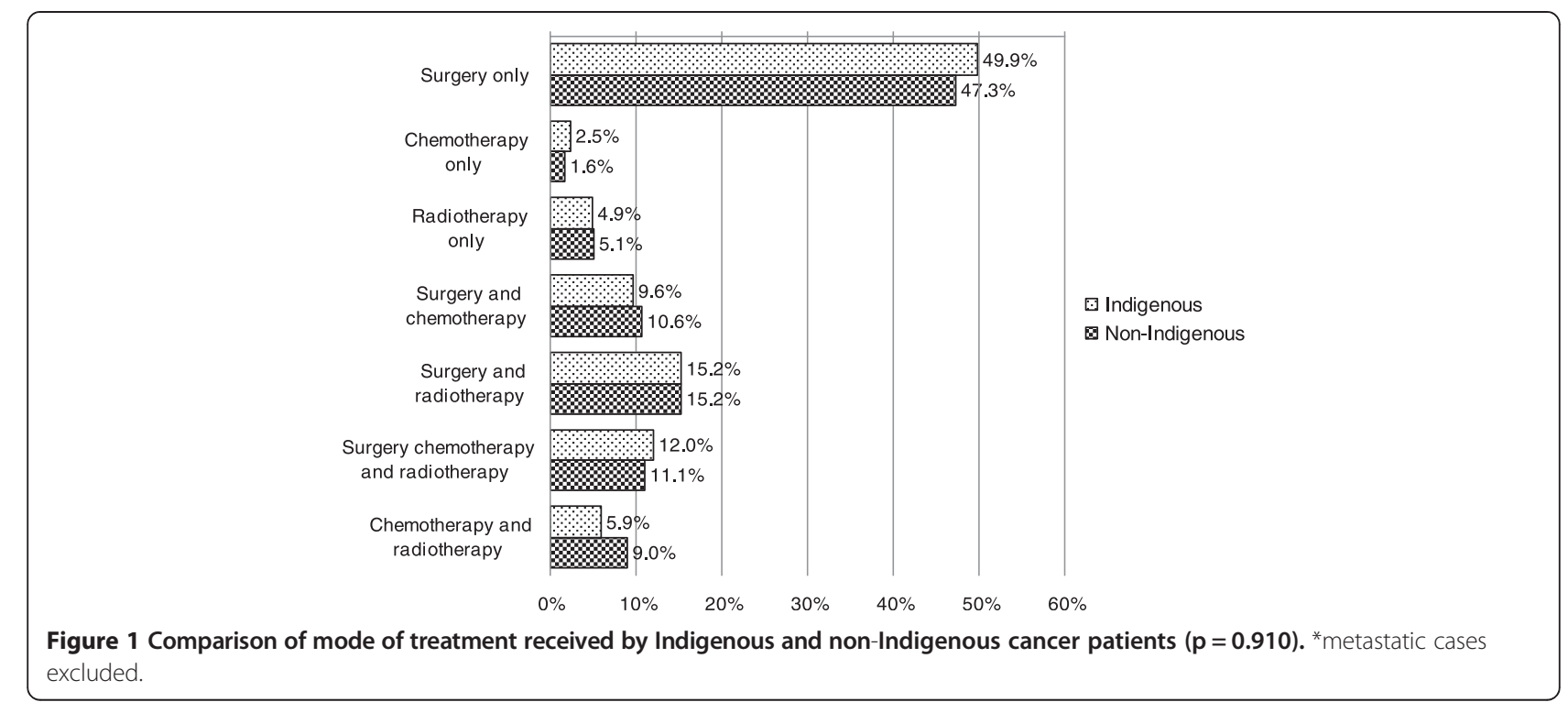

Comorbidity Index (e.g. mental illness, alcoholism), factors which might preclude cancer treatment.

Our findings regarding treatment parallel reports from a number of international [22-24] and local [6,25-27] studies. We found that irrespective of remoteness or socioeconomic advantage, Indigenous people received less treatment than non-Indigenous counterparts (including Indigenous people who were most advantaged). Factors such as miscommunication and social and cultural differences between patients and health care providers $[28,29]$, poor understanding of medical advice [30], inherent racism in the health system [31], lack of transport

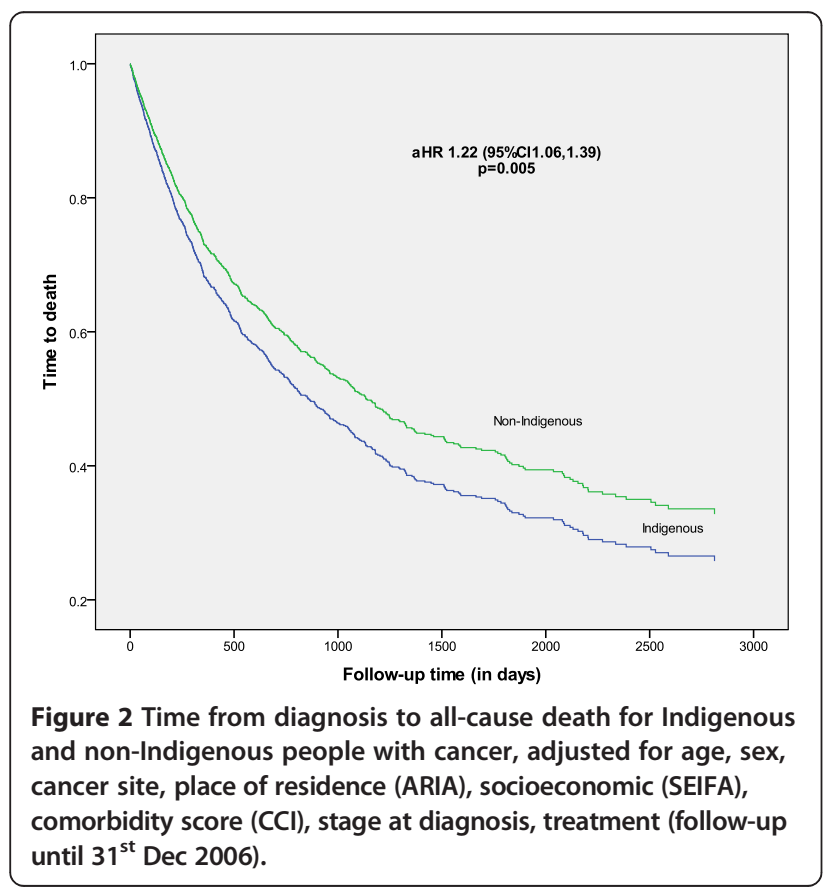

Table 2 Odds of receiving treatment in Indigenous compared to non-Indigenous (referent group) cancer patients: all cases and stratified by comorbidity score $\wedge$

\begin{tabular}{|c|c|}
\hline \multicolumn{2}{|c|}{ Any treatment } \\
\hline Stratified by: & comorbidity score 0 \\
\hline & comorbidity score 1 \\
\hline & comorbidity score 2 \\
\hline
\end{tabular}

\section{Curative treatment \#}

$\begin{array}{ll}\text { Stratified by: } & \text { comorbidity score } 0 \\ & \text { comorbidity score } 1 \\ & \text { comorbidity score } 2+\end{array}$

\section{Curative surgery \#}

Stratified by: $\quad$ comorbidity score 0

$$
\text { comorbidity score } 1
$$

Adjusted $\mathrm{OR}^{*}(95 \% \mathrm{Cl})$

$0.46(0.41,0.63)$

$0.36(0.23,0.57)$

$0.43(0.23,0.81)$

$0.73(0.39,1.34)$

$0.74(0.56,1.00)$

$0.76(0.46,1.03)$

$0.55(0.28,1.09)$

$1.29(0.65,2.55)$

$0.82(0.62,1.07)$

$0.68(0.48,0.97)$

$0.86(0.46,1.60)$

$1.49(0.74,2.91)$

Curative chemotherapy \#

$0.72(0.53,098)$

Stratified by:

comorbidity score 0

$0.79(0.55,1.13)$

comorbidity score 1

$0.62(0.30,1.28)$

comorbidity score $2+$

$0.36(0.12,1.07)$

$0.82(0.63,1.07)$

Curative radiotherapy \#

$0.88(0.64), 1.23)$

Stratified by

$$
\begin{aligned}
& \text { comorbidity score } 0 \\
& \text { comorbidity score } 1 \\
& \text { comorbidity score } 2+
\end{aligned}
$$

$0.56(0.29,1.08)$

$0.66(0.31,1.42)$

*Adjusted for age, sex, remoteness, socioeconomic status, stage, comorbidity score.

\# metastatic cases excluded.

$\wedge$ Comorbidity Score: 0 (no known comorbidity), 1 (Charlson index of 1) or $2+$ (Charlson index of 2 or more). 

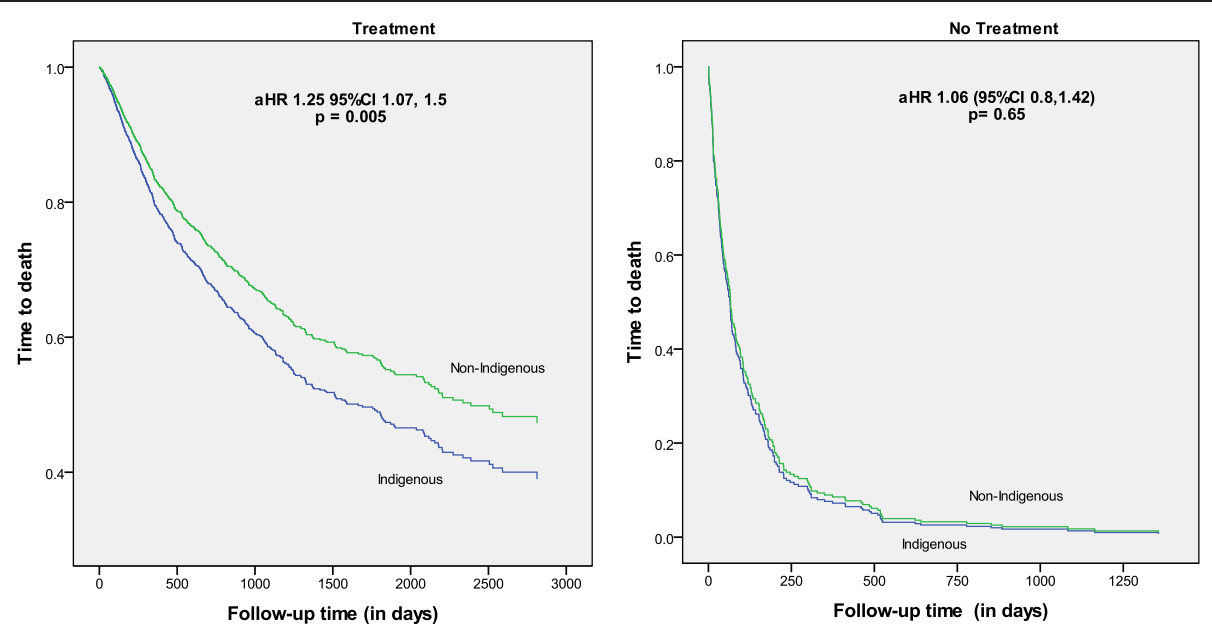

Figure 3 Time from diagnosis to all-cause death for Indigenous and non-Indigenous people with respect to treatment, adjusted for age, sex, cancer site, place of residence (ARIA), socioeconomic (SEIFA), comorbidity score (CCl), stage at diagnosis, treatment (Follow-up until $31^{\text {st }}$ Dec 2006).

[32], geographic isolation [33], and lack of Indigenous support persons [34], have been cited as some of the reasons for treatment disparity. We found no delay for patients receiving treatment in public hospitals, in contrast to earlier studies which reported a significant difference in time to surgery [6] and delays in treatment $[18,35]$. We also report that the presence of diabetes or elevated $\mathrm{HbA} 1 \mathrm{C}$ did not influence treatment uptake and that chemotherapy completion rates for those receiving treatment for non-metastatic cancer, were similar for both groups.

A greater proportion of Indigenous people in our cohort had died before the end of the follow-up period, and they were twice as likely to have died from a noncancer death. These results are consistent with the poor cancer survival and higher mortality that have been reported for Indigenous people with cancer elsewhere [36-39]. Unadjusted analysis indicated a lower survival observed among Indigenous compared to non-Indigenous people (all causes, non-cancer and cancer deaths) and the survival differential for cancer death remained apparent when adjusted for confounding factors (age, sex, remoteness, stage, socioeconomic status and comorbidities). When further adjusted for diabetes and/or treatment, the differential reduced to borderline significance, suggesting these factors may be associated with lower survival. Despite this, we found that overall Indigenous people who had treatment fared worse than non-indigenous people who had treatment, suggesting either the type or quality of treatment, or other non-treatment factors at play in overall treatment outcomes.

Survival was worse for Indigenous people in the first year after diagnosis. After adjustment for stage and comorbidities, the survival differential persisted in the first year but, when adjusted for treatment alone, this difference was no longer apparent. Treatment differences

Table 3 Proportional hazard ratios, using Cox regression models, of time to death for all cancer diagnosed between 1998 and 2004, for Indigenous compared to non-Indigenous people in Queensland, Australia

\begin{tabular}{|c|c|c|c|c|c|}
\hline & & HR & $(95 \% \mathrm{Cl})$ & $\mathrm{aHR}^{*}$ & $(95 \% \mathrm{Cl})$ \\
\hline All cause death & & 1.37 & $(1.22,1.55)$ & 1.22 & $(1.06-1.39)$ \\
\hline Non-cancer death & & 2.39 & $(1.57,3.63)$ & 1.95 & $(1.17,3.24)$ \\
\hline Cancer death & & 1.30 & $(1.15,1.48)$ & 1.10 & $(0.96,1.27)$ \\
\hline \multirow[t]{5}{*}{ Time to death (all causes) by years: } & $0-1 \mathrm{yr}$ & 1.60 & $(1.37,1.87)$ & 1.33 & $(1.12,1.83)$ \\
\hline & $1-2 y$ & 0.98 & $(0.73,1.33)$ & 1.18 & $(0.85,1.65)$ \\
\hline & $2-3 y r$ & 0.98 & $(0.76,1.26)$ & 0.98 & $(0.77,1.26)$ \\
\hline & 3- $4 \mathrm{yr}$ & 0.97 & $(0.74,1.30)$ & 1.03 & (0.79 1.36) \\
\hline & 4- $5 \mathrm{yr}$ & 1.05 & $(0.76,1.45)$ & 1.02 & $(0.72,1.45)$ \\
\hline
\end{tabular}

*Adjusted for: Sex, Age, Comorbidity Score (Modified Charlson Comorbidity Index): 0, 1, 2+; Accessibility/Remoteness Index of Australia 1 = Highly accessible/ Accessible 2 = Moderately accessible $3=$ Remote/Highly remote; SEIFA (Socioeconomic Index for Areas): $1=$ Most disadvantaged, $2=$ Intermediate advantage, $3=$ Most advantaged; Stage: 1 = Localised, 2 = Regional Spread, $3=$ Metastatic Disease, $9=$ Not sure; Any treatment. 
and, to a lesser extent, stage and comorbidities, may be important contributing factors for the poorer outcomes immediately after cancer diagnosis among Indigenous people. Our findings are similar to a recent Queensland report which included patients treated at public and private hospitals [2]; Indigenous people were 1.5 times more likely to die in the first year of diagnosis than nonIndigenous people, but with excess mortality limited to the first two years of follow-up after diagnosis. Although that study was much larger than the present one, it was limited by a lack of information on cancer stage, comorbidities and cancer treatment. Our results, adjusted for treatment, stage and comorbidities, suggest that differences in treatment between the two groups are mainly responsible for the survival differential in the first year after a cancer diagnosis.

Misidentification of Indigenous status in Queensland public hospitals is known to be around 12\% [40]. As Indigenous status was checked in the medical record review and discrepancies investigated where possible, we are confident that misclassification in the study sample is minimal. Matching resulted in little differences in the distribution of age, sex or cancer type between the two groups, however, as perfect matching was not possible, it resulted in the inclusion of a higher proportion of Indigenous people who lived very remotely and were severely disadvantaged. Of note, $27 \%$ of Indigenous people in this study were from the more remote regions, whereas $22 \%$ of the Indigenous population resident in Queensland live in these regions [41]. This minimizes the concern that Indigenous people from remote regions, who potentially have inadequate access to the health care system, might have been underrepresented in this study. The chief strength in utilizing data from the National Death Index (NDI) for vital status is the virtually complete population coverage. Standardized and consistent data collection by the NDI ensures that the death data are of high quality (93.7\% sensitivity and $100 \%$ specificity for the identification of deaths) [42]. Nevertheless, if a few cases were missed due to reporting delays to the NDI, they are not likely to be differentially biased by Indigenous status.

\section{Conclusions}

This comprehensive investigation of the patterns of care of Indigenous people with cancer, confirmed that Indigenous people had more advanced stage at diagnosis, more comorbidities, received less treatment, and had poorer survival than their non-Indigenous counterparts. In addition, we found that survival disparity in the first year after diagnosis was likely to be related to lack of cancer treatment. However, Indigenous people receiving cancer treatment had poorer outcomes overall, despite comparable time to commencement, duration, and amount of treatment received. We also identified a subset of untreated patients who might reasonably be considered candidates for cancer treatment. A greater understanding of the interplay between overall health, demographic features and cancer, as well as Indigenous people's awareness of cancer and cancer treatment, is therefore required. Indigenous cancer patients have particular needs that should be considered when planning cancer care, particularly during the first year after diagnosis.

\section{Competing interests}

The authors declare that they have no competing interests.

\section{Authors' contributions}

S P Moore a participated in the conception, design, analyses of the data, interpretation of results, writing and editing the manuscript. A Green participated in the conception, design, analyses of the data, interpretation of results and editing the manuscript. F Bray assisted in editing the manuscript. $G$ Garvey participated in the interpretation of results and editing the manuscript. J Martin participated in the interpretation of results and editing the manuscript. M Coory participated in the conception, design, analyses of the data, interpretation of results. P Valery participated in the conception, design, analyses of the data, interpretation of results and editing the manuscript. We confirm that all authors have seen and approved its final version.

\section{Acknowledgements}

S. Moore was supported by a National Health and Medical Research Council (NHMRC) Training Scholarship for Indigenous Australian Health Research (No. 389935) and an International Agency for Research on Cancer-Cancer Council Australia post-doctoral fellowship. The NHMRC Project Grant (No. 1004643) partly funded this project. S Moore and P Valery were also supported by the former Australian Centre for International and Tropical Health, UQ. A Green was partly supported by a Fellowship from the UK Medical Research Council (No. 89912). PC Valery was supported by an Australian Research Council Future Fellowship (No. 100100511). This work was produced as part of the In-Kind activities of the Lowitja Institute incorporating the Cooperative Research Centre for Aboriginal and Torres Strait Islander Health. We thank Dr Isabelle Soerjomataram for her analytical advice. We thank the members of the Indigenous Reference Group established to inform the study investigators about cultural matters and translation of results to the community. The authors declare that they have no competing interests.

\section{Author details}

${ }^{1}$ Menzies School of Health Research, 147 Wharf St, Spring Hill, Brisbane 4000, Australia. ${ }^{2}$ Cancer and Population Studies Group, Queensland Institute of Medical Research, 300 Herston Rd, Herston, 4006 Brisbane, Australia. ${ }^{3}$ University of Manchester, Manchester Academic Health Science Centre, Manchester, UK. International Agency for Research on Cancer, 150 Cours Albert Thomas, 69372 Lyon, France. 5 Murdoch Children's Research Institute, Melbourne, Victoria, Royal Children's Hospital, Flemington Road, Parkville, Melbourne 3052, Australia. ${ }^{6}$ School of Medicine University of Queensland Translational Research Institute, 37 Kent ST, Woolloongabba 4071, Melbourne, Australia. ${ }^{7}$ Monash University (Adjunct), Melbourne, Australia.

Received: 28 May 2014 Accepted: 4 July 2014

Published: 18 July 2014

\section{References}

1. Condon JR, Armstrong BK, Barnes A, Cunningham J: Cancer in Indigenous Australians: a review. Cancer Causes Control 2003, 14(2):109-121.

2. Cramb SM, Garvey G, Valery PC, Williamson JD, Baade PD: The first year counts: cancer survival among Indigenous and non-Indigenous Queenslanders, 1997-2006. Med J Aust 2012, 196(4):270-274.

3. Chong A, Roder D: Exploring differences in survival from cancer among Indigenous and non-Indigenous Australians: implications for health service delivery and research. Asian Pac J Cancer Prev 2010, 11(4):953-961.

4. Condon J: Cancer and Indigenous Australians in the Northern Territory. In PhD thesis. Darwin: Charles Darwin University; 2004. 
5. South Australian Cancer Registry: Epidemiology of cancer in South Australia. Adelaide: South Australian Cancer Registry; 1997:1-19.

6. Valery PC, Coory M, Stirling J, Green AC: Cancer diagnosis, treatment, and survival in Indigenous and non-Indigenous Australians: a matched cohort study. Lancet 2006, 367(9525):1842-1848

7. Moore SP, Green AC, Garvey G, Coory MD, Valery PC: A study of head and neck cancer treatment and survival among indigenous and non-indigenous people in Queensland, Australia, 1998 to 2004. BMC Cancer 2011, 11:460.

8. Australian Bureau of Statistic: Hospital Statistics: Aboriginal and Torres Strait Islander Australians 1997-98. In Occasional Paper 4711. Canberra: ABS; 2000.

9. Charlson ME, Pompei P, Ales KL, Mackenzie CR: A new method of classifying prognostic comorbidity in longitudinal studies: development and validation. J Chronic Dis 1987, 40(5):373-383.

10. Commonwealth Department of Health and Aged Care: Measuring remoteness: Accesssibility/Remoteness Index of Australia (ARIA) In Occasional papers: New series number 14. Edited by Commonwealth Department of Health and Aged Care and National Key Centre for Socia Applications of Geographical Information Systems, vol. 14. Canberra: Commonwealth Department of Health and Aged Care; 2001.

11. Australian Bureau of Statistics: Information Paper: Socio-Economic Indexes for Areas (SEIFA) 2001. In Vol. Vol 2039. Canberra: Australian Bureau of Statistics; 2003

12. American Joint Committee on Cancer: Comparison Guide: Cancer Staging Manual. Fifth versus Sixth Edition. Chicago: American Joint Committee on Cancer; 2003.

13. Cox DR: Regression Models and Life-Tables. J R Stat Soc Ser B Methodol 1972, 34(2):187-220.

14. World Health Organisation: Use of Glycated Haemoglobin (HbA1C) in the diagnosis of diabetes mellitus. In Geneva: World Health Organisation; 2011:1-26.

15. Condon JR, Barnes T, Armstrong BK, Selva-Nayagam S, Elwood JM: Stage at diagnosis and cancer survival for Indigenous Australians in the Northern Territory. Med J Aust 2005, 182(6):277-280.

16. Janssen-Heijnen ML, Smulders S, Lemmens VE, Smeenk FW, van Geffen HJ, Coebergh JW: Effect of comorbidity on the treatment and prognosis of elderly patients with non-small cell lung cancer. Thorax 2004, 59(7):602-607.

17. Sarfati D, Hill S, Blakely T, Robson B, Purdie G, Dennett E, Cormack D, Dew K The effect of comorbidity on the use of adjuvant chemotherapy and survival from colon cancer: a retrospective cohort study. BMC Cancer 2009, 9:116.

18. Stevens W, Stevens G, Kolbe J, Cox B: Ethnic differences in the management of lung cancer in New Zealand. J Thorac Oncol 2008, 3(3):237-244.

19. Hill S, Sarfati D, Blakely T, Robson B, Purdie G, Chen J, Dennett E, Cormack D, Cunningham R, Dew K, McCreanor T, Kawachi I: Survival disparities in Indigenous and non-Indigenous New Zealanders with colon cancer: the role of patient comorbidity, treatment and health service factors. J Epidemiol Community Health 2010, 64(2):117-123.

20. Coory MD, Green AC, Stirling J, Valery PC: Survival of Indigenous and non-Indigenous Queenslanders after a diagnosis of lung cancer: a matched cohort study. Med J Aust 2008, 188(10):562-566.

21. Martin JH, Coory MD, Valery PC, Green AC: Association of diabetes with survival among cohorts of Indigenous and non-Indigenous Australians with cancer. Cancer Causes Control 2009, 20(3):355-360

22. Flum DR, Stuart S, Wilcox M: Processes and Outcomes of Care Among Navajo Women With Breast Cancer. J Am Med Assoc 2003, 290(15):1996-1997.

23. Hede K: Agencies Look to Patient Navigators To Reduce Cancer Care Disparities. J Natl Cancer Inst 2006, 98(3):157-159.

24. Goggins WB, Wong GKC: Poor Survival for US Pacific Islander Cancer Patients: Evidence From the Surveillance, Epidemiology, and End Results Database: 1991 to 2004. J Clin Oncol 2007, 25(36):5738-5741.

25. Coory M, Green A, Stirling J, Valery P: Survival of Indigenous and non-Indigenous Queenslanders after a diagnosis of lung cancer: a matched cohort study. Med J Aust 2008, 188(10):563-566

26. Cunningham J: Diagnostic and therapeutic procedures among Australia hospital patients identified as Indigenous. Med J Aust 2002, 176:58-62.

27. Hall SE, Bulsara CE, Bulsara MK, Leahy TG, Culbong MR, Hendrie D, Holman CD: Treatment patterns for cancer in Western Australia: does being Indigenous make a difference? Med J Aust 2004, 181(4):191-194.
28. Cass A, Lowell A, Christie M, Snelling PL, Flack M, Marrnganyin B, Brown I: Sharing the true stories: improving communication between Aboriginal patients and healthcare workers. Med J Aust 2002, 176(10):466-470.

29. Lowenthal R, Grogan P, Kerrins E: Reducing the impact of cancer in Indigenous communities: ways forward. Med J Aust 2005, 182:3.

30. McMichael C, Kirk M, Manderson L, Hoban E, Potts H: Indigenous women's perceptions of breast cancer diagnosis and treatment in Queensland. Aust N Z J Public Health 2000, 24(5):515-519.

31. Vos T, Barker B, Begg S, Stanley L, Lopez AD: Burden of disease and injury in Aboriginal and Torres Strait Islander Peoples: the Indigenous health gap. Int J Epidemiol 2008

32. Australian Bureau of Statistics: The health and welfare of Australia's Aboriginal and Torres Strait Islander peoples 2005. In Edited by Australian Bureau of Statistics and Australian Institute of Health and Welfare. Canberra: Australian Bureau of Statistics; 2005

33. Coory M, Thompson A, Ganguly I: Cancer among people living in rural and remote Indigenous communities in Queensland. MJA 2000 173:301-304.

34. Thompson SC, Shahid S, Bessarab D, Durey A, Davidson PM: Not just bricks and mortar: planning hospital cancer services for Aboriginal people. BMC Res notes 2011, 4:62.

35. Rogers D, Petereit DG: Cancer disparities research partnership in Lakota Country: clinical trials, patient services, and community education for the Oglala, Rosebud, and Cheyenne River Sioux tribes. Am J Public Health 2005, 95(12):2129-2132.

36. Andreasyan K, Hoy WE: Patterns of mortality in Indigenous adults in the Northern Territory, 1998-2003: are people living in more remote areas worse off? Med J Aust 2009, 190(6):307-311.

37. Condon JR, Barnes T, Cunningham J, Armstrong BK: Long-term trends in cancer mortality for Indigenous Australians in the Northern Territory. Med J Aust 2004, 180(10):504-507.

38. Espey DK, Wu XC, Swan J, Wiggins C, Jim MA, Ward E, Wingo PA, Howe HL, Ries LA, Miller BA, Jemal A, Ahmed F, Cobb N, Kaur JS, Edwards BK: Annual Report to the Nation on the Status of Cancer, 1975-2004, Featuring Cancer in American Indians and Alaska Natives. Cancer 2007. 110(10):2119-2152

39. Supramaniam R, Grindley $\mathrm{H}$ : Cancer in Indigenous people of New South Wales - a response to: Cancer in Indigenous Australians: a review. Cancer Causes Control 2005, 16:321-322.

40. Australian Institute of Health and Welfare: Indigenous identification in hospital separations data-quality report. In Health Services Series Series no. 35. Cat no. HSE 85. Canberra: AlHW: 2010.

41. Australian Bureau of Statistics: Population Distribution, Aboriginal and Torres Strait Islander Australians 2006. Edited by Australian Bureau of Statistics. Darwin: Australian Bureau of Statistics; 2007

42. Magliano D, Liew D, Pater H, Kirby A, Hunt D, Simes J, Sundararajan V Tonkin A: Accuracy of the Australian National Death Index: comparison with adjudicated fatal outcomes among Australian participants in the Long-term Intervention with Pravastatin in Ischaemic Disease (LIPID) study. Aust N Z J Public Health 2003, 27(6):649-653.

doi:10.1186/1471-2407-14-517

Cite this article as: Moore et al:: Survival disparities in Australia: an analysis of patterns of care and comorbidities among indigenous and non-indigenous cancer patients. BMC Cancer 2014 14:517.

\section{Submit your next manuscript to BioMed Central and take full advantage of:}

- Convenient online submission

- Thorough peer review

- No space constraints or color figure charges

- Immediate publication on acceptance

- Inclusion in PubMed, CAS, Scopus and Google Scholar

- Research which is freely available for redistribution 